\title{
Autonomous decision-making for antenatal screening in Pakistan: views held by women, men and health professionals in a low-middle income country
}

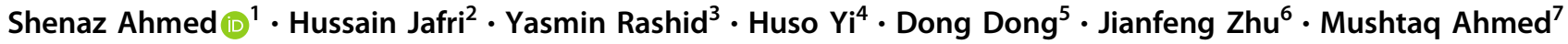

Received: 3 October 2018 / Revised: 17 December 2018 / Accepted: 11 January 2019 / Published online: 4 February 2019

(c) European Society of Human Genetics 2019

\begin{abstract}
Prenatal genetic technologies now are being implemented in LMICs, and while there is much research on the ethical, legal and social implications of such technologies in Western countries, there is a paucity of such research in LMICs, which have diverse cultural, religious, political, financial and health service contexts. This study aimed to explore views about women's autonomous decision-making for antenatal screening held by women, men and healthcare professionals (HCPs) in Pakistan. A Q-methodology study was conducted during June 2016 to January 2018 in Lahore, Pakistan. A total of 137 participants (60 women, 57 men, $20 \mathrm{HCPs}$ ) rank-ordered 41 statements. Following by-person factor analysis, four distinct viewpoints were identified. Three of these represent views held by women and men only: autonomous decision-making requires directive advice from doctors; autonomous decision-making requires the husband's involvement, where independent decision-making by the woman is considered culturally inappropriate; and opting for antenatal screening is a foregone decision. One contrasting viewpoint represents predominantly HCPs: autonomous decision-making is the couple's responsibility. These findings highlight that Western approaches to facilitating women's autonomy for antenatal screening are unlikely to be suitable for use in Pakistan. Instead, culturally appropriate practice guidelines are needed in LMICs to enable HCPs to adopt shared decision-making approaches in a way that enables them to facilitate active and joint decisionmaking by couples, while ensuring women exercise their autonomy.
\end{abstract}

\section{Introduction}

In Western countries, prenatal genetic technologies are usually implemented in clinical practice after much consideration of the empirical evidence on the ethical, legal and social issues (ELSIs). These technologies are now being implemented more globally [1], including within low-tomiddle income countries (LMICs), which have diverse

Shenaz Ahmed

s.ahmed@leeds.ac.uk

1 University of Leeds, Leeds, UK

2 Genetech Laboratory, Lahore, Pakistan

3 Central Park Medical College, Lahore, Pakistan

4 National University of Singapore, Singapore, Singapore

5 Chinese University of Hong Kong, Shatin, New Territories, China

6 Fudan University, Shanghai, China

7 Yorkshire Regional Genetics Service, Leeds, UK cultural, religious, political, financial and health service contexts, yet there is sparse empirical evidence of the ELSIs specific to LMICs. For example, in Pakistan, screening for foetal anomalies, ranging from nuchal translucency scans for soft markers for Down syndrome to non-invasive prenatal testing for multiple conditions, is available. In the province of Punjab, the government-funded Punjab Thalassaemia Prevention Project (PTPP, 2009) also includes carrier and antenatal screening. While the need for informed reproductive choice is acknowledged in Pakistan, there is an absence of policy and practice guidelines on how to facilitate autonomous decision-making for antenatal screening in this or any other LMIC [2].

Policy and practice guidelines in Western/higher income countries on antenatal screening focus on supporting the woman as an independent decision-maker [3], emphasising an individualistic approach that encompasses independence, self-determination and self-sufficiency [4]. This approach may safeguard women from paternalistic influences and undue pressure from relatives and healthcare professionals (HCPs), but it does not take into account that individuals 
may not view themselves as independent decision-makers [5]. For example, early feminist critiques of the Western autonomy paradigm recognise women's autonomy as 'relational', where her agency in moral decision-making is inevitably social, shaped by the viewpoints of people she is close to [6]. Similarly, decision-making in Pakistan is likely to be rooted in religious beliefs, family-centred and require support from the doctor [7]. Given that currently available guidelines worldwide operationalise Western ideologies of individualism, to facilitate women's autonomous decisionmaking about antenatal screening in Pakistan and other LMICs with collectivist cultures, there is an imperative need to develop more culturally appropriate policy and practice guidelines [5].

Women in LMICs generally have limited autonomy over their healthcare decisions [8], and men are discouraged from being involved in pregnancy-related matters because these are seen as falling primarily within a female domain [9]. Instead, female in-laws play a pivotal role in decisions about prenatal care [10]. However, recent research on decision-making about antenatal screening in LMICs shows that most women would prefer to make decisions with their partner and oppose the involvement of in-laws [5], possibly because the father's views about termination of pregnancy and fathering a child with a disability are major factors in women's decision-making, and because women may want to share the moral implications of screening with the father [11]. The importance of decision-making with the partner to enhance women's autonomy in pregnancy is recognised [9], particularly by proponents of relational autonomy who believe shared decision-making can better support women by preventing feelings of helplessness and isolation [12]. The need for research in LMICs on men's views about women's autonomy in maternal healthcare [13], including antenatal screening [5], is also acknowledged.

HCPs also have a significant role in facilitating autonomous decision-making. In contrast to the non-directive role of HCPs in decision-making for antenatal/genetic screening in Western countries [3], the role of the doctor in LMICs is usually directive [2]. In LMICs, patients tend to delegate decisions to the doctor and expect him/her to take a paternalistic approach [7, 14]. Such patient expectations raise ethical concerns about patient autonomy and highlight the need for research on HCPs' views about their role in decision-making and women's autonomy for antenatal screening.

The development of culturally appropriate policy and practice guidelines for use in LMICs to enhance pregnant women's autonomy requires research with different stakeholders. Therefore, this study aimed to explore views about women's autonomous decision-making for antenatal screening held by women, men and HCPs in Pakistan.

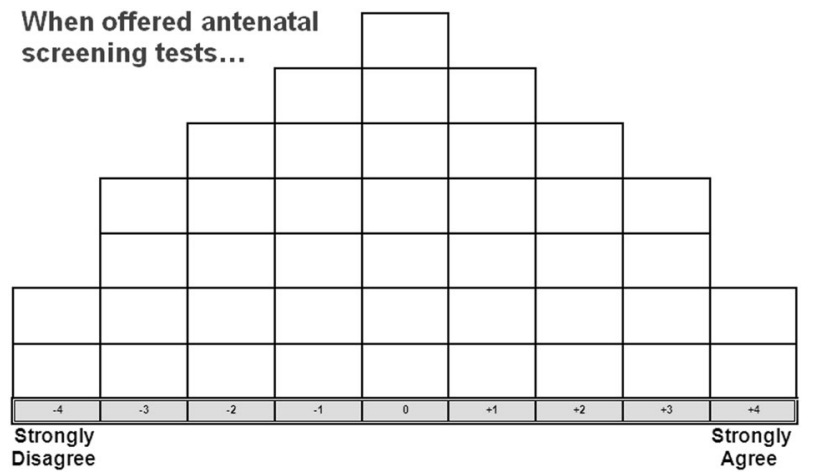

Fig. 1 The Q-sorting grid

\section{Materials and methods}

This study was carried out during June 2016 to January 2018 using Q-methodology, a structured approach to exploring the diversity of views on a topic [15]. Participants' views are obtained through their $Q$-sorts - their distribution of statements (things already written or said about the topic) rank ordered on a Q-grid-(Fig. 1) to show the extent of agreement or disagreement with each statement [16]. The set of statements (Q-set) used in this study had been previously developed for a UK study (in English and Urdu) [17]. For details of how the Q-set was developed, see the UK study [17]. For use with HCPs, the statements were reworded to obtain their views on how women should make decisions: 'I would' and 'I/my/me' were changed to 'She should' and 'she/her', respectively.

\section{Participants}

Following ethical approval from the Pakistan Medical Association, the study was conducted in Lahore, Pakistan, with three groups: women, men and HCPs. In Lahore, antenatal screening services are predominantly provided by the private sector or free of charge by NGOs and the PTPP. Sixty Pakistani women were previously recruited as part of an international study [5]. To explore the diversity of views specific to a LMIC, the present study included the 60 Pakistani women from the international study, plus 57 men and 20 HCPs (14 females, 6 males). Men and HCPs were recruited immediately after the women, but before completion of the study with the women. Women and men were not related/couples. All women and men had at least one child aged 3 years or younger to ensure salience of the research topic. Purposive sampling was used to recruit women and men, and to ensure sample diversity by age and education. Participants' religious affiliation was not recorded because they were likely to be Muslims. Convenience sampling was used to recruit the HCPs (all practicing 
Table 1 Demographic characteristics of study participants $(n=137)$

\begin{tabular}{clll}
\hline & $\begin{array}{l}\text { Women } \\
n=60\end{array}$ & $\begin{array}{l}\text { Men } \\
n=57\end{array}$ & $\begin{array}{l}\text { HCPs } \\
n=20\end{array}$ \\
\hline Participants' education $N(\%)$ & & & \\
Up to matriculation level* & $16(27 \%)$ & $16(28 \%)$ & - \\
Above matriculation level & $44(73 \%)$ & $41(72 \%)$ & $20(100 \%)$ \\
Age in years, mean (SD) & $28(5.3)$ & $35(6.3)$ & $33(9.4)$ \\
\hline
\end{tabular}

*Matriculation level is equivalent to UK GCSE level at around age 16 years

obstetricians) attending a research workshop in a University Hospital in Lahore. See Table 1 for sample characteristics.

\section{Procedure}

Women and men were recruited via hospitals and community maternal and child health centres. Local research assistants, trained by the first author in Q-methodology data collection, collected data in person using standardised instructions, where Q-sorts were completed individually by men and women in convenient locations (place of recruitment or participants' homes). The first author recruited HCPs, who completed Q-sorts individually within a group setting.

Participants were provided with a Q-set (41 statements individually printed on numbered cards) and a Q-grid, in Urdu for women and men (Pakistan's national language) and English for HCPs (language of the research workshop). Participants ranked the statements from +4 (strongly agree) to -4 (strongly disagree), in relation to the offer of antenatal screening tests by placing each statement on a cell on the Q-grid. Participant's distribution of the statements (the Q-sort) was photographed. Post-sorting data included participant explanations for placing statements on +4 and -4 , either via an audio recorded post-sorting interview (women and men) or in writing on a separate document (HCPs). A total of 137 participants completed the Q-sorting procedure.

\section{Analysis}

A participant's $Q$-sort is the unit of analysis in Qmethodology. Data were analysed using by-person factor analytic techniques in PQ-Method to identify factorsgroups of Q-sorts based on the similarities and differences, in which participants ranked statements [16, 18]. Each factor represents a distinguishable viewpoint and interpretation of these enables identification of the diversity of views in the sample [19]. Factors were extracted using principal components analysis, which maximises similarities within factors and difference between them. Varimax rotation was used to ensure that no Q-sort loaded significantly at the same level on more than one factor [15].

Participants with Q-sorts exemplifying each factor (exemplars) were identified; Q-sorts with a loading of \pm 0.4 $(p<0.01)$ on one factor only [15]. These exemplars were merged to produce a factor array, a single 'ideal' Q-sort that best represented each factor (Table 2) [20]. Factor arrays are the key output of the statistical analysis and for each factor represent how a participant with a correlation coefficient of 1 would have ranked the 41 statements. Interpretation of the pattern of ranked statements within each factor array enables identification of different viewpoints.

Eight factors were originally extracted, with an eigenvalue of 1.00 or more, and a minimum of one exemplar [20]. A four-factor solution was reached after inspection of factors five to eight showed that they did not provide distinct viewpoints that were not captured in the other four factors.

Interpretation of factors involved examining and comparing factor arrays, focussing on statements in the 'strongly agree' and 'strongly disagree' columns, and statements identified as statistically distinguishing each factor. Post-sorting data were then used to inform, confirm or challenge and further clarify factor interpretations. The first author initially interpreted the factors, discussed them with the co-authors and refined them.

\section{Results}

For demographic information for the exemplars in the four factors (viewpoints), see Table 3. Quotations in this section will be followed by participants' codes, providing information about participant group $(\mathrm{F}=$ female, $\mathrm{M}=$ male, $\mathrm{HCP}=$ Healthcare Professional).

There was one consensus statement showing participants tended to strongly agree with doctors giving professional advice about antenatal screening.

Viewpoint 1: Decision-making requires directive advice from doctors

Q-sorts of 17 participants exemplified this factor: nine women, eight men. Seven women and six men had an education level higher than matriculation (equivalent to UK GCSE level).

The main emphasis was on doctors as directive advisors, with comparatively little emphasis on the need for the couple to engage in the decision-making process, mainly because antenatal testing was perceived as an important aspect of antenatal care.

Participants believed doctors should give directive professional advice $(\# 40=+3 ; \# 8=+3)$. They would want information about tests ( $\# 27=+4)$, but would not necessarily want to make the decision themselves $(\# 6=-3$; $\# 39=-2)$. 
Table 2 Factor arrays: scores against each statement by viewpoint

\begin{tabular}{|c|c|c|c|c|c|}
\hline No. & Statement & $\mathrm{V} 1$ & $\mathrm{~V} 2$ & $\mathrm{~V} 3$ & V4 \\
\hline 1 & $\begin{array}{l}\text { It's best to take one step at a time- }- \text { to have the tests and not worry about what } \\
\text { could happen. }\end{array}$ & 3 & 1 & 3 & 0 \\
\hline 2 & $\begin{array}{l}\text { It is important for me to think about the challenge of bringing up a child with the } \\
\text { condition. }\end{array}$ & 2 & 2 & 3 & \\
\hline 3 & $\begin{array}{l}\text { I think the offer of tests suggests people with these conditions are worth less than } \\
\text { others. }\end{array}$ & -2 & -4 & -1 & -1 \\
\hline 4 & I would worry about the child with the condition being treated badly by society. & -3 & -2 & 1 & \\
\hline 5 & I would look for what my religion says about having such testing. & -1 & 3 & 2 & \\
\hline 6 & I would not discuss testing with anyone because the decision is mine alone. & -3 & -2 & 0 & -2 \\
\hline 7 & I would be angry if I was tested without being asked for my permission. & -2 & 2 & 0 & \\
\hline 8 & $\begin{array}{l}\text { Doctors/midwives should give me their professional advice about whether to } \\
\text { have testing. }\end{array}$ & 3 & 2 & 0 & \\
\hline 9 & I would leave the decision about testing to doctors/midwives. & 1 & -3 & -1 & -3 \\
\hline 10 & If lots of other people are having testing, then testing would be fine by me. & 0 & 0 & 2 & -1 \\
\hline 11 & $\begin{array}{l}\text { The decision about these tests is no more difficult to make than routine health } \\
\text { tests in pregnancy, such as the mother's blood pressure or diabetes. }\end{array}$ & 2 & 1 & 2 & -1 \\
\hline 12 & $\begin{array}{l}\text { There is no decision for me to make because the tests are just part of good care for } \\
\text { pregnant women. }\end{array}$ & 3 & 3 & 3 & -2 \\
\hline 13 & It is difficult for me to say 'no' to testing when doctors/midwives offer it. & 2 & -3 & 1 & 1 \\
\hline 14 & I would take lots of time to make a decision about testing. & -4 & -2 & -3 & \\
\hline 15 & Having too much information about the tests makes it difficult to make decisions. & 0 & -1 & -2 & \\
\hline 16 & $\begin{array}{l}\text { I find it hard to make a decision about testing because there are too many } \\
\text { decisions to make in pregnancy. }\end{array}$ & 0 & 0 & -2 & 0 \\
\hline 17 & I would discuss it with my partner/husband but the decision would be mine. & 1 & -3 & 0 & 2 \\
\hline 18 & $\begin{array}{l}\text { I would not want to go against my partner/husband's wishes, so if we disagree, I } \\
\text { would do what he wants. }\end{array}$ & -1 & 4 & 1 & -2 \\
\hline 19 & Me and my partner/husband should make the decision about testing together. & 2 & 4 & 2 & 4 \\
\hline 20 & I would keep my in-laws out of the process of making the decision about testing. & -2 & -4 & 0 & 0 \\
\hline 21 & I would take advice from my parents or brothers/sisters about having the tests. & -1 & 2 & -1 & 0 \\
\hline 22 & My parents' or brothers'/sisters' views would sway my decision about testing. & -3 & 0 & -1 & 0 \\
\hline 23 & My in-laws' views would influence my decision about testing. & -1 & -3 & -2 & -1 \\
\hline 24 & $\begin{array}{l}\text { I think doctor's/midwife's should give information only, not advice about } \\
\text { whether to have testing. }\end{array}$ & 1 & -1 & -2 & 2 \\
\hline 25 & $\begin{array}{l}\text { I believe doctors/midwives would not offer the tests if it wasn't important to have } \\
\text { them. }\end{array}$ & 2 & 2 & 4 & 3 \\
\hline 26 & I believe having these tests is just part of being a good mother. & 4 & 3 & 4 & 1 \\
\hline 27 & $\begin{array}{l}\text { I would want information provided by doctors/midwives to help me make my } \\
\text { decision about testing. }\end{array}$ & 4 & 3 & 2 & 4 \\
\hline 28 & I would consider myself fortunate to be offered these tests free of charge. & 1 & 0 & 1 & 1 \\
\hline 29 & I would worry about what others might think if I decided to terminate a child. & -3 & -1 & -2 & -2 \\
\hline 30 & $\begin{array}{l}\text { I should not be asking the doctor or midwife to make a decision about whether or } \\
\text { not I have testing. }\end{array}$ & 0 & 0 & 0 & -1 \\
\hline 31 & I value the opportunity to think about termination of a child with a condition. & -1 & 0 & 3 & 1 \\
\hline 32 & If I cannot decide whether to have testing then I should not be tested. & 0 & 1 & -1 & -1 \\
\hline 33 & $\begin{array}{l}\text { Decisions about testing should only be made after carefully thinking through all } \\
\text { the possible consequences of testing. }\end{array}$ & 0 & 1 & 1 & 3 \\
\hline 34 & $\begin{array}{l}\text { I would worry about people judging me as being irresponsible if I decide not to } \\
\text { have testing. }\end{array}$ & 0 & -1 & 1 & -2 \\
\hline 35 & I would not have an abortion, so there's no point in having testing. & 1 & -2 & -4 & 0 \\
\hline 36 & I would accept the child that God gives me so there is no reason to have testing. & -2 & 1 & -4 & -4 \\
\hline
\end{tabular}


Table 2 (continued)

\begin{tabular}{|c|c|c|c|c|c|}
\hline No. & Statement & V1 & $\mathrm{V} 2$ & V3 & V4 \\
\hline 37 & I want information about the tests but I do not want to make the decision. & -1 & 0 & -3 & -3 \\
\hline 38 & $\begin{array}{l}\text { I do not want information from doctor's/midwife's - I will use my own } \\
\text { judgement. }\end{array}$ & -4 & -2 & -3 & -3 \\
\hline 39 & My partner/husband should make the decision about testing. & -2 & -1 & -1 & -3 \\
\hline 40 & Doctors should tell me what to do, not ask me to make the decision about testing. & 3 & 1 & 0 & -4 \\
\hline 41 & $\begin{array}{l}\text { I prefer not to make the decision about testing because I am scared of making the } \\
\text { wrong decision. }\end{array}$ & 1 & -1 & -3 & \\
\hline
\end{tabular}

Table 3 Demographic information for exemplars in the five viewpoints

\begin{tabular}{lllll}
\hline & $\begin{array}{l}\text { Viewpoint } 1 \\
\text { exemplars } \\
n=17\end{array}$ & $\begin{array}{l}\text { Viewpoint 2 } \\
\text { exemplars } \\
n=18\end{array}$ & $\begin{array}{l}\text { Viewpoint 3 } \\
\text { exemplars } \\
n=23\end{array}$ & $\begin{array}{l}\text { Viewpoint 4 } \\
\text { exemplars } \\
n=20\end{array}$ \\
\hline $\begin{array}{l}\text { Participant group } \\
\quad \text { Women }\end{array}$ & 9 & 12 & 11 & 5 \\
$\quad \begin{array}{l}\text { Men } \\
\text { HCPs }\end{array}$ & 8 & 6 & 12 & 3 \\
$\begin{array}{l}\text { Participants' education, } \\
\quad N\end{array}$ & - & - & 12 \\
$\quad \begin{array}{l}\text { Up to matriculation } \\
\text { level* }\end{array}$ & 4 & 8 & 4 & - \\
$\quad \begin{array}{l}\text { Above } \\
\text { matriculation level }\end{array}$ & 13 & 10 & 19 & 20 \\
$\begin{array}{l}\text { Age in years, mean } \\
\text { (range) }\end{array}$ & 30 (19-41) & 29 (19-40) & 34 (20-46) & 34 (27-46) \\
\hline
\end{tabular}

*Matriculation level is equivalent to UK GCSE level at around age 16 years
This may explain why men and women strongly disagreed with using their own judgement and taking lots of time to make a decision $(\# 14=-4 ; \# 38=-4)$ and showed little interest in the opportunity to think about termination of a child with a condition $(\# 31=-1)$. Participants explained that this was because they would opt for a termination, if advised to do so by their doctor: "Our doctor is our saviour and s/he would only suggest tests that are necessary" (F63).

Participants strongly believed having antenatal screening tests was an important aspect of good antenatal care $(\# 26=$ +4 ; $\# 1=+3$; $\# 11=+2$ ). Accordingly, they believed there was no decision for them to make $(\# 12=+3)$ and would find it difficult to say 'no' to testing $(\# 13=+2)$. Also, they were unlikely to be concerned about being tested without consent or consideration of the consequences of testing (\#7 $=-2$; \#33 =0): “I wouldn't be angry because they would only do tests that are best for me" (F31).

Furthermore, participants would not be concerned about the views of relatives or what others may think if they opted for termination of pregnancy $(\# 22=-3$; $\# 29=-3)$. They also disagreed with accepting the child that God gives and placed little emphasis on religious perspectives about testing $(\# 36=-2 ; \# 5=-1)$ : "Religion doesn't come into it. Testing is a separate matter" (M13).
Participants holding this viewpoint would delegate the decision about testing to doctors $(\# 9=+1)$. However, their accounts also show that they would want to retain ultimate control and would not want to be forced to test against their will $(\# 37=-1)$.

Viewpoint 2: Decision-making requires the husband's involvement

Q-sorts of 18 participants exemplified this factor: twelve women and six men. Six women and four men had a higher education level than matriculation level.

The husband's involvement in decision-making was considered essential, and independent decision-making by the woman was considered culturally inappropriate. Similar to the other viewpoints, participants strongly agreed that the husband and wife should make the decision about testing together $(\# 19=+4)$. However, in contrast, participants most strongly agreed with women not going against their husband's wishes and doing what he wants $(\# 18=+4)$ and most strongly disagreed with the decision being the woman's (\#17 = -3). Participants' accounts show that they considered it culturally inappropriate for women to make decisions independently: "In our culture, wives comply with their husband and don't make decisions without him" (M50); "I'd discuss testing with my husband and only get it done if he agrees" (F15). 
Yet somewhat paradoxically, participants disagreed with the husband making the decision about testing $(\# 39=-1)$. So participants believed women should make decisions with the husband, but equally, the decision was not solely the husband's.

Also, unlike the other viewpoints, participants tended to most strongly disagree with keeping in-laws out of the decision-making process $(\# 20=-4)$, but also disagreed with in-law's views influencing their decisions $(\# 23=-3)$. The juxtaposition of these statements and participants' accounts suggest that these participants may not exclude in-laws from conversations about antenatal screening and may even seek their advice, but in-laws were not considered central to decision-making: "They are the parents of the husband... it's good to have their advice" (M05).

Furthermore, participants strongly agreed with looking for what religion says about such testing and were most likely to agree with accepting the child that God gives (\#5 $=+3$; \#36 = +1). Nevertheless, in contrast, they seemed to have favourable attitudes towards antenatal testing and termination of pregnancy, believing that doctors would not offer tests if it was not important to have them $(\# 25=+2$; $\# 32=+1 ; \# 11=+1 ; \# 1=+1$ ). Participants most strongly disagreed with the idea that the offer of tests suggested that people with these conditions are worth less than others (\#3 = -4) and similar to some of the other viewpoints, believed that having these tests was part of good care for pregnant women and being a good mother $(\# 12=+3$; $\# 26=+3$ ). Participants would also want directive professional advice $(\# 40=+1 ; \# 38=-2 ; \# 24=-2)$.

Viewpoint 3: Opting for antenatal screening is a foregone decision

Q-sorts of 23 participants exemplified this factor: 11 women and 12 men. Nine women and ten men had a higher education level than matriculation level.

Participants strongly agreed with there being no decision for them to make $(\# 12=+3)$, emphasising the importance of testing to identify conditions in early pregnancy, so that they may opt for termination of pregnancy. Accordingly, they most strongly disagreed with being 'scared of making the wrong decision' (\#41 = -3) and disagreed with it being difficult to make a decision about testing and taking lots of time $(\# 15=-2 ; \# 16=-2 ; \# 14=-3)$. Participants also most strongly agreed with having tests as 'part of being a good mother' $(\# 26=+4)$, further endorsing antenatal testing as a forgone decision.

Participants most strongly disagreed with not having an abortion (\#35 = -4) and most strongly agreed with valuing the opportunity to think about termination of an affected pregnancy $(\# 31=+3)$. This was because they considered children with conditions to be a burden for parents and society: "Parents of a child who is not normal suffer as much as the child, especially as they know they could have done something to prevent it" (M21).

Unlike the other viewpoints, there was little focus on who should make the decision about testing, although participants generally agreed with joint decision-making by the couple $(\# 19=+2 ; \# 18=+1)$ and showed little interest in the woman as an independent decision-maker $(\# 6=0 ; \# 17$ $=0$ ). Also, participants would value information and advice from doctors $(\# 27=+2 ; \# 24=-2)$ and would want to make this decision themselves $(\# 37=-3)$. They placed little emphasis on directive professional advice $(\# 8=0$; $\# 40=0$ ), possibly because they believed opting for antenatal screening was a foregone decision.

Participants holding this viewpoint also most strongly disagreed that they 'would not have an abortion, so there's no point in having testing' (\#35 = -4) and with accepting the child that God gives (\#36=-4). Participants believed that God gives knowledge and wisdom to avoid 'suffering' for the child and parents: "We should use science and technology to have children who can lead a normal life" (M23).

Viewpoint 4: Decision-making is the responsibility of the couple

Q-sorts of 20 participants exemplified this factor: five women, three men and twelve HCPs (all female). All participants had a higher education level than matriculation level. HCPs were exemplars in this viewpoint only, and not in any other viewpoint.

Participants' emphasised decision-making about antenatal screening as a parental responsibility, where couples should make joint decisions $(\# 19=+4)$. Participants explained this was because subsequent decisions would need to be made by both parents, including invasive testing, termination of pregnancy or raising a child with a condition: “...they have to face the consequences together" (HCP12).

Participants rejected the idea that women 'do not want to make the decision' and most strongly disagreed with the husband making the decision $(\# 37=-3 ; \# 39=-3)$. However, there was also little emphasis on the woman as the main or independent decision-maker, as in Western countries, or the father as the main decision-maker, as in the literature on healthcare decision-making in low-middleincome countries.

In contrast to the other viewpoints, participants seemed to endorse the concept of informed decision-making. They strongly agreed with the provision of information for decision-making $(\# 27=+4)$ and most strongly disagreed with there being no decision for them/women to make and the decision about these tests being no more difficult to make than routine health tests in pregnancy $(\# 12=-2 ; \# 11$ $=-1$ ). These participants were also least likely to endorse the statement 'it's best to take one step at a time, to have the tests and not worry about what could happen' $(\# 1=0)$, and 
explained that discussion of the implications of antenatal test results was not necessary at the time of testing. Furthermore, participants were least likely to endorse the statement that having tests was just part of being a good mother $(\# 26=+1)$. Instead, they most strongly endorsed only making screening decisions after careful consideration $(\# 33=+3)$. Unlike the other viewpoints, participants were most likely to agree that they would/couples should take lots of time to make a decision and most strongly disagree with doctors telling them/women what to do $(\# 14=+1$; $\# 40=-4)$. Participants also agreed that doctors should give their professional advice $(\# 24=+2 ; \# 8=+2)$, but only in the form of information provision, where they should avoid being directive: "Doctors should only give information, not influence decisions. It's entirely the couple's decision" (HCP07).

As in some of the other viewpoints, participants strongly agreed that they/women would look to what religion says about having such testing $(\# 5=+3)$, but also strongly disagreed with accepting the child that God gives ( $\# 36=$ -4): “Having faith in God is positive, but you don't have to accept everything" (M37).

\section{Discussion}

The four distinct viewpoints elicited in this study about women's autonomous decision-making for antenatal screening show the views held by the participants-women, men and HCPs in Pakistan. All the viewpoints represent the range of views expressed by women and men, and viewpoint 4 represents the views expressed by HCPs. Although viewpoint 4 also represents a comparatively small number of women and men, viewpoints 1 and 4 show that women and men generally had different views about autonomous decision-making than HCPs.

Similar to other studies [5], [17], viewpoint 1 shows that while women and men would want to be informed about antenatal screening, they were likely to want doctors' directive advice. Most of the women and men in our study had educational qualifications higher than the equivalent to UK GCSE level, yet still perceived the need for directive advice. The literacy level in the Punjab province of Pakistan is $\sim 60 \%$, with millions of people over the age of 15 years unable to read or write [21], so the tendency for couples to seek directive advice is likely to be high. In light of the growing availability of prenatal genetic technologies in LMICs, our findings suggest there will be an increased need for HCPs to provide directive advice about antenatal screening in LMICs.

In contrast, in viewpoint 4 , HCPs believed it was the couple's responsibility to make decisions about antenatal screening based on their own circumstances and values of the conditions. Similar to studies in Western countries, HCPs believed their role was to facilitate decision-making by providing information only' [22] not to provide directive advice. HCPs endorsed parents' autonomy for screening decisions, including non-directiveness, but participants' expectations of directive advice for antenatal screening raises ethical challenges for HCPs. Non-directiveness is considered a 'gold standard' for respecting patient autonomy, but insisting that couples make antenatal screening decisions themselves when they are vulnerable and dependent on HCPs advice that could be seen as undermining their autonomy [12, 23]. Therefore, HCPs should enable couples to become active participants in decision-making by encouraging them to express their values, being attentive to their views, then acting in the best interest of the couple [24].

Our findings suggest that there is a need to develop culturally appropriate practice guidelines for use in LMICs to enable HCPs to adopt shared decision-making approaches, particularly for couples lacking confidence in their own decision-making. We acknowledge the challenges in adopting such an approach to autonomous decision-making in populations with low literacy levels and where HCPs may believe they themselves lack knowledge of genetics and new technologies [25]. Therefore, to inform the development of practice guidelines on facilitating autonomous decision-making in LMICs, research is needed on (i) how HCPs should facilitate decision-making, particularly in populations with low literacy levels and (ii) HCPs training needs to engage in shared decision-making about antenatal screening.

Within all of the viewpoints in our study, participants generally agreed with the woman and her husband making joint decisions. Research in Western countries also shows that women want to involve their partner in decision-making and that partners want to be involved [11, 17, 26, 27], so these findings are not specific to LMICs. However, unlike studies in Western countries, none of the viewpoints provide support for the woman as an independent decision-maker. Furthermore, viewpoint 2 is represented predominantly by women who endorsed the key role of men in decision-making. This endorsement and missing discourse on women's autonomy may be simply because parents would prefer to make joint decisions, as in various cultures and countries [17, 26], or because it is culturally inappropriate for women to consider themselves as independent decision-makers in a patriarchal society [9]. However, participants generally disagreed with the decision being the husband's. Also, there was generally a lack of discourse on the role of other family members in decisionmaking, particularly female in-laws, except in viewpoint 2 , where it was clear that they would only be informed out of respect. 
These findings suggest that the use of Western individualistic approaches focusing on the woman's autonomy are unlikely to be suitable for use in Pakistan, where cultural norms emphasise the primacy of the husband in decisionmaking. However, we are not aware of any reference to involving fathers in decision-making for antenatal screening in policy or practice guidelines in any country. Instead, such guidelines operationalise Western ideologies of individualism worldwide, overlooking alternative (including feminist) perspectives of women's autonomy, such as relational approaches. Relational approaches in which family members are involved in healthcare decision-making could enhance patients' autonomy and there are calls in Western countries for HCPs in antenatal/genetic services to move towards a more nuanced approach, utilising relational approaches to autonomy to better support women [12, 23]. To empower women in Pakistan and other LMICs in a culturally appropriate way, further research is needed to understand how relational approaches could be adopted to facilitate a joint decision-making approach for couples. Research on how to involve the father in screening decisions should focus on how to empower women, ensuring that women's autonomy is not constrained through deference to men and that women are not marginalised.

The finding that participants may perceive the option of antenatal screening as a forgone decision because of the burden of having a child with a condition is understandable given the broader cultural context in LMICs. In addition to the lack of medical, educational and social welfare facilities for people with disabilities, there is stigma associated with having such a child, parents may experience social isolation and the child may be seen as a form of divine retribution for parental wrong-doing [28]. Nevertheless, our findings resonate with the ethical implications of routine antenatal screening [29], where the offer of antenatal screening tests could be perceived as their endorsement by HCP. Therefore, there is need for HCPs to facilitate active decisionmaking to enable parents to make autonomous reproductive decisions.

Unlike other studies [5, 17], there was a lack of focus on the religious context of antenatal screening. Participants tended to agree with looking for what religion says about antenatal screening, but disagreed with accepting the child that God gives. The former may reflect a social desirability bias, while the latter is based on beliefs that Islam encourages the pursuit of knowledge and to exercise autonomy [30], and possibly the social context mentioned above [28]. Therefore, HCPs should acknowledge parents' need for religious information, but avoid interpretation of this as their rejection of antenatal screening. These findings provide further support for encouraging parents to engage in active decision-making to exercise their autonomy.
To our knowledge, this is the first study to explore the views of men and HCPs on women's autonomy in decisionmaking about antenatal screening in a LMIC. Practical constraints limited recruitment of participants to one major city in Pakistan. Also, most of the participants had an educational qualification higher than the equivalent to UK GCSE level, so the sample does not reflect the general population in Pakistan. Research with a less educated Pakistani sample may reveal further viewpoints, although the lack of emphasis on independent decision-making is unlikely to change. Further research is also needed on the degree to which these views are prevalent in the wider Pakistani population and other LMICs.

This study begins to address the paucity of research on ELSIs of prenatal genetic technologies in LMICs, highlighting the need for culturally appropriate practice guidelines that adopt relational approaches to autonomy. Our findings also have implications beyond the LMIC context, raising questions about the lack of 'relationality' embedded in the current 'gold standard' of Western individualistic guidelines.

Acknowledgements This research was funded by: the University of Leeds, UK and Central Park Medical College, Lahore, Pakistan.

\section{Compliance with ethical standards}

Conflict of interest The authors declare that they have no conflict of interest.

Publisher's note: Springer Nature remains neutral with regard to jurisdictional claims in published maps and institutional affiliations.

\section{References}

1. Chandrasekharan S, Minear MA, Hung A, Allyse M. Noninvasive prenatal testing goes global. Sci Transl Med. 2014;6:231fs215.

2. Zhong A, Darren B, Dimaras H. Ethical, social, and cultural issues related to clinical genetic testing and counseling in low- and middle-income countries: a systematic review. Genet Med. 2018. https://doi.org/10.1038/s41436-018-0090-9.

3. Public Health England. NHS fetal anomaly screening programme handbook, 2018. Accessed 18 Dec. 2018. https://assets.publishing. service.gov.uk/government/uploads/system/uploads/attachment_da ta/file/749742/NHS_fetal_anomaly_screening_programme_ha ndbook_FINAL1.2_18.10.18.pdf.

4. Kim SYH. Autonomy and the relational self. Philos Psychiatr Psychol. 2013;20:183-5.

5. Ahmed S, Yi H, Dong D, Zhu J, Jafri H, Rashid Y, et al. Interpretations of autonomous decision-making in antenatal genetic screening among women in China, Hong Kong and Pakistan. Eur J Hum Genet. 2018;26:495-504.

6. Mackenzie C, Stolijar N. Feminist Perspectives on Automony, Agency, and the Social Self.. Oxford: Oxford University Press; 2000.

7. Moazam F. Families, patients, and physicians in medical decision making: a Pakistani perspective. Hastings Cent Rep. 2000;30:28-37. 
8. Osamor PE, Grady C. Women's autonomy in health care decisionmaking in developing countries: a synthesis of the literature. Int $\mathrm{J}$ Women's Health. 2016;8:191-202.

9. Mumtaz Z, Salway S. Understanding gendered influences on women's reproductive health in Pakistan: moving beyond the autonomy paradigm. Soc Sci Med. 2009;68:1349-56.

10. Mumtaz Z, Salway SM. Gender, pregnancy and the uptake of antenatal care services in Pakistan. Sociol Health Illn. 2007;29:1-26.

11. Dheensa S, Metcalfe A, Williams RA. Men's experiences of antenatal screening: a metasynthesis of the qualitative research. Int J Nurs Stud. 2013;50:121-33.

12. Samuel GN, Dheensa S, Farsides B, Fenwick A, Lucassen A. Healthcare professionals' and patients' perspectives on consent to clinical genetic testing: moving towards a more relational approach. BMC Med Ethics. 2017;18:47.

13. Tokhi M, Comrie-Thomson L, Davis J, Portela A, Chersich M, Luchters S. Involving men to improve maternal and newborn health: a systematic review of the effectiveness of interventions. PLoS ONE. 2018;13:e0191620.

14. Jafarey AM, Farooqui A. Informed consent in the Pakistani milieu: the physician's perspective. J Med Ethics. 2005;31:93-6.

15. Watts S, Stenner P. Doing Q methodology: theory, method, and interpretation. Qual Res Psychol. 2005;2:67-91.

16. Brown SQ. Methodology and qualitative research. Qual Health Res. 1996;4:561-7.

17. Ahmed S, Bryant LD, Tizro Z, Shickle D. Interpretations of informed choice in antenatal screening: A cross-cultural, Qmethodology study. Soc Sci Med. 2012;74:997-1004.

18. Schmolck P. PQ Method Download Page for Windows Users (version 2.35). 2014; http://www.lrz-muenchen.de/ schmolck/ qmethod/downpqx.htm

19. Kitzinger C. The Social Construct of Lesbianism. Bristol: Sage; 1987.
20. Brown SR. Political Subjectivity: Applications of Q methodology in political science. New Haven: Yale University Press; 1980.

21. Rehman A, Jingdong L, Hussain I. The province-wise literacy rate in Pakistan and its impact on the economy. Human Soc Sci. 2015;1:140.

22. Ahmed S, Bryant LD, Cole P. Midwives' perceptions of their role as facilitators of informed choice in antenatal screening. Midwifery. 2013;29:745-50.

23. Entwistle VA, Carter SM, Cribb A, McCaffery K. Supporting patient autonomy: the importance of clinician-patient relationships. J Gen Intern Med. 2010;25:741-5.

24. Malik AY. Physician-researchers' experiences of the consent process in the sociocultural context of a developing country. AJOB Prim Res. 2011;2:38-46.

25. Ahmed S, Jafri H, Rashid Y, Mason G, Ehsan Y, Ahmed M. Attitudes towards non-invasive prenatal diagnosis among obstetricians in Pakistan, a developing, Islamic country. Prenat Diagn. 2017;37:289-95.

26. Skirton H, Barr O. Antenatal screening and informed choice: a cross-sectional survey of parents and professionals. Midwifery. 2010;26:596-602.

27. Atkin K, Berghs M, Dyson S. 'Who's the guy in the room?' Involving fathers in antenatal care screening for sickle cell disorders. Soc Sci Med. 2015;128:212-9.

28. Ahmed S, Bryant LD, Ahmed M, Jafri H, Raashid Y. Experiences of parents with a child with Down syndrome in Pakistan and their views on termination of pregnancy. J Community Genet. 2013;4:107-14.

29. Kater-Kuipers A, de Beaufort ID, Galjaard RH, Bunnik EM. Ethics of routine: a critical analysis of the concept of 'routinisation' in prenatal screening. J Med Ethics. 2018;44:626-31.

30. Mustafa Y. Islam and the four principles of medical ethics. J Med Ethics. 2014;40:479-83. 